\title{
Methodological Considerations for Studies in Sport and Exercise Science with Women as Participants: A Working Guide for Standards of Practice for Research on Women
}

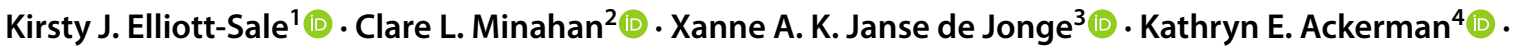

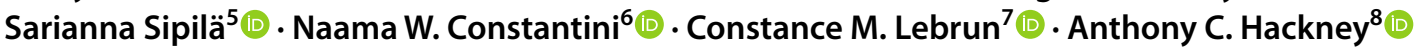

Accepted: 6 February 2021 / Published online: 16 March 2021

(c) The Author(s) 2021

\begin{abstract}
Until recently, there has been less demand for and interest in female-specific sport and exercise science data. As a result, the vast majority of high-quality sport and exercise science data have been derived from studies with men as participants, which reduces the application of these data due to the known physiological differences between the sexes, specifically with regard to reproductive endocrinology. Furthermore, a shortage of specialist knowledge on female physiology in the sport science community, coupled with a reluctance to effectively adapt experimental designs to incorporate female-specific considerations, such as the menstrual cycle, hormonal contraceptive use, pregnancy and the menopause, has slowed the pursuit of knowledge in this field of research. In addition, a lack of agreement on the terminology and methodological approaches (i.e., gold-standard techniques) used within this research area has further hindered the ability of researchers to adequately develop evidenced-based guidelines for female exercisers. The purpose of this paper was to highlight the specific considerations needed when employing women (i.e., from athletes to non-athletes) as participants in sport and exercise science-based research. These considerations relate to participant selection criteria and adaptations for experimental design and address the diversity and complexities associated with female reproductive endocrinology across the lifespan. This statement intends to promote an increase in the inclusion of women as participants in studies related to sport and exercise science and an enhanced execution of these studies resulting in more high-quality female-specific data.
\end{abstract}

\section{Introduction}

\subsection{Statement of the Problem}

Across the lifespan, circulating concentrations of oestrogen and progesterone change from puberty, through adulthood, until menopause, when a dramatic decline in the secretion of ovarian steroids occurs and cyclic oestrogen production is replaced by a low constant production by the ovaries. Furthermore, between puberty and menopause, circulating concentrations of oestrogen fluctuate fivefold and progesterone greater than 50 -fold over a 21 - to 35 -day cycle (i.e., menstrual cycle). Indeed, these cyclical acute fluctuations in ovarian hormones across the menstrual cycle may be altered by external factors (e.g., hormonal contraceptives [HC], circadian variation, diet, exercise), clinical conditions

Kirsty J. Elliott-Sale

kirsty.elliottsale@ntu.ac.uk

Extended author information available on the last page of the article

\section{Key Points}

Not all 'women' are the same. Women have a variety of reproductive hormonal profiles that change across the lifespan from puberty to the menopause.

The endogenous hormonal profile of women is frequently influenced by exogenous sources, such as hormonal contraceptives (HC) and hormone replacement therapy (HRT).

Depending on the research question, women should be recruited on pre-defined, standardised criteria, which, in most cases, should be retrospectively confirmed (i.e., homogenous a priori inclusion and a posteriori exclusion criteria).

Depending on the research question, the experimental design needs to be adapted in line with the hormonal milieu (e.g., consideration of menstrual cycle phase, type of HC used, stage of menopause). 
(e.g., functional hypothalamic amenorrhea, polycystic ovary syndrome) and pregnancy (Fig. 1; [1]).

In addition to reproductive function, ovarian steroids have been shown to target a number of tissues (e.g., epithelial, connective, muscle and nervous; [2-4]) and influence an array of biological processes (e.g., metabolism, ventilation, immunity, cognition, gastrointestinal, cardiovascular, autonomic regulation, and genitourinary function; [5-13]). As such, different concentrations of circulating ovarian steroids throughout the lifespan and across the menstrual cycle (with and without dysfunction and/or manipulation) might significantly influence the mechanisms that control and regulate cell function and integrated physiologic adaptation in women.

Given the potential influence of ovarian hormones on multiple biological systems, it is reasonable to assume that the heterogeneic findings observed among studies conducted with women as participants, particularly those examining physiological responses to exercise and adaptations to training, may be attributable to the numerous hormonal profiles a woman may experience during her lifetime. As such, it is important that scientists consider the potential effects of ovarian hormones throughout the lifespan on exercise responses and sports performance and apply suitable methodology to their studies in order to control these effects and reduce the heterogeneic results. Nonetheless, for decades scientists have avoided conducting sport and exercise research with women as participants due, in part, to the complex methodological considerations required and/or the difficulty in interpreting the heterogeneic results often observed within and among studies. Consequently, research

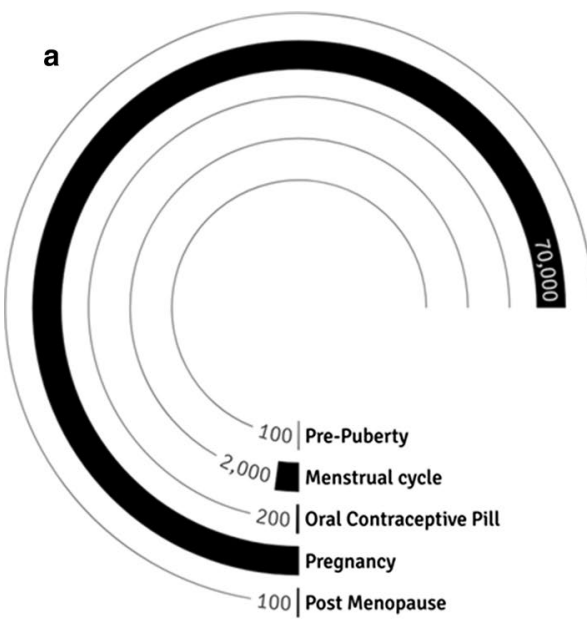

Fig. 1 Indicative oestrogen and progesterone profiles across the lifespan from childhood to senescence: a oestrogen $\left(\mathrm{pmol} \cdot \mathrm{L}^{-1}\right)$. With regards to oestrogen, the menstrual cycle has 20 times more oestrogen than pre-puberty and pregnancy 35 times more oestrogen than the menstrual cycle; b progesterone $\left(\mathrm{nmol} \cdot \mathrm{L}^{-1}\right)$. The menstrual cycle has 35 times more progesterone than pre-puberty and pregnancy almost 7 findings from sport and exercise performance and training studies with men only as participants are applied to women, which can result in a missed opportunity for women to reach their athletic and performance potential. In order to guide scientists and practitioners through the complexities of: $i$. identifying the maturation status and menstrual-cycle status of women participants, and $i i$. designing studies that provide insight into the difference in the physiological responses to exercise among the various hormonal profiles of women, guidance on the definition(s) of sampled populations is required and a working guide for standards of practice for research in this field is warranted.

\subsection{Current State of the Art}

Research into the effects of the menstrual cycle on the exercise response has being ongoing since at least 1876, when Professor Mary Jacobi won the Harvard University Boylston Prize Essay for her observations on menstruation and physical work and rest [14]. Despite a recent growing interest in research in sport and exercise science with women as participants, the overall research quantity in this area is still very small compared to research with men as participants [15]. Therefore, the effects of oestrogen and progesterone on women's responses to exercise and adaptations to training are still not fully understood. As a result, there are no sport and exercise-related guidelines for training and nutrition which are customised for sportswomen (i.e., athletes and exercisers) and underpinned by sufficient, high-quality scientific evidence. Numerous reviews [e.g., 16-20], books

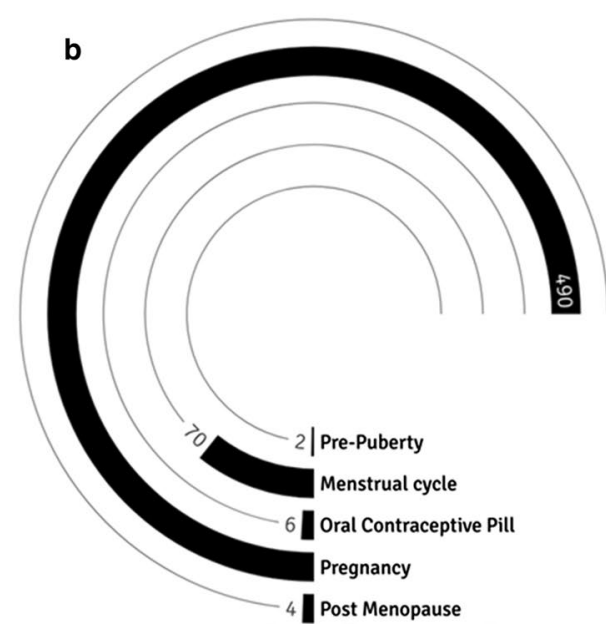

times more progesterone than during the menstrual cycle. Oral contraceptives users and post-menopausal women have similar levels of endogenous oestrogen and progesterone. Hypothalamic-pituitary forms of amenorrhea (not depicted here) do not show any evidence of oestrogen production based on urinary measurements [1]. In women, "oestrogen" includes the oestrone, oestradiol, oestriol hormones 
[e.g., 21-23] and meta-analyses [e.g., 24,25] have summarised and examined data from this field spanning almost 50 years, but all have concluded that more, better quality studies are needed before a consensus on the effects of ovarian steroids on training and performance can be reached.

It is clear that more research focusing on areas unique to female physiology is required to inform best practice guidelines for training and nutrition [24, 25]. There are some studies, however, that have demonstrated clear and recurring findings of ovarian-steroid interference with biological processes that may affect athletic performance (i.e., responses to exercise and adaptation to, and recovery from, training), which highlight the importance of considering ovarian steroid profiles in sport and exercise science research. In particular, the manipulation of endogenous ovarian steroid levels with synthetic hormones (i.e., HC) has been repeatedly associated with increased markers of muscle damage in women after unaccustomed eccentric exercise [8, 26-30]. Therefore, knowledge of the use of $\mathrm{HC}$ by athletes or research participants is imperative in understanding the recovery process after an acute bout of exercise or adaptation to training. There is a strong body of evidence indicating altered thermoregulation in women taking $\mathrm{HC}$ during exercise including altered skin blood flow and cutaneous vasodilation, as well as a delayed onset of sweating and a higher internal temperature threshold [31-35]. As such, ovarian hormone interference via the administration of $\mathrm{HC}$ may have implications for exercise in the heat. Oestrogen is often associated with substrate oxidation and utilisation during prolonged exercise. The notion that elevated plasma oestrogen concentrations increase the reliance on fat as an energy source during endurance exercise is a consistent observation [6, 36-38]. Despite these few convincing findings, whether disturbances to these physiological mechanisms result in a decrement to performance in strength, speed, and/or endurance events remains to be elucidated. It should be also noted that there is always at least one study that opposes the findings of the majority and as newer formulations of synthetic hormones are developed, there will be further ambiguity in the findings. Therefore, the importance of considering a woman's current ovarian hormonal profile in sport and exercise science research is paramount.

\subsection{The Gap in the Field}

Rather than viewing the dynamic profiles of ovarian steroids in women as a reason to exclude them from sport and exercise science research, future studies need to explore the specific effects of oestrogen and progesterone and related hormonal ageing on physiological function and ergo athletic performance across the lifespan in women. Female-specific research is needed as the number of women participating in sport and exercise is increasing in many countries, and parity in the Olympics and Paralympics is approaching (i.e., equal number of male and female competitors and medals). For example, in 1900 only $2.2 \%$ of the competitors in the Olympics were female; in 1952 the proportion was $10.5 \%$, in 2000 it was $38.2 \%$ and in 2021 it is predicted to be $48.8 \%$. If male-based research continues to be applied to females, there is a risk that the true potential of women will not be achieved as the potential influence of ovarian hormones remains unclear; herein exist the gap in the field and the fundamental statement of the problem within contemporary sport and exercise science. At the elite level, understanding the effects of oestrogen and progesterone on body systems and performance may produce the marginal gain needed for success. In addition, there is a need to understand the effects of training on hypothalamic, pituitary and ovarian hormones and related outcomes, such as body composition and bone [39]. At the recreational level, understanding the impact of changes in ovarian hormone concentration, experienced during the menstrual cycle or as a result of menstrual irregularities, hormonal contraceptive use, pregnancy or the menopause, on the ability and willingness to undertake exercise and physical activity may help reduce the disproportionate decline in sports participation seen at puberty in girls [40, 41]. This decrease in physical activity often extends into adulthood, and is compounded during pregnancy and the postpartum period [22], and as such has implications for health and well-being [42] for women of all ages. Among middle-aged women, menopausal hormonal changes are associated with deterioration of the body systems [43], performance and functioning [44], but further understanding is needed of the magnitude and timing of these changes as well as the role of physical activity and exercise to overcome or attenuate these changes.

In order to facilitate a new generation of quality research in sport and exercise science with women as participants that addresses the current gap in the field, direction is needed on the best and most accurate types of research design to employ in this field. In addition, guidance on the definition(s) of sampled populations is required in order to improve the uniformity of studies involving women. As such, this article is intended to serve as a working guide for standards of practice for research on women.

Synchronous with changes in performance, ovarian steroids exert many clinical effects, which have also received less attention in sport and exercise medicine-based research. Examples include hyponatremia, which is more prevalent in females than males [45] and heat stroke, which is influenced by ovarian hormonal concentrations [46]. Although this paper is focused on studies related to sport and exercise science, some of the approaches described herein may be also relevant for female-based sport and exercise medicinebased research. 


\subsection{Background to the Statement}

In the early 2000s, articles started to provide critical commentary on the methodological approach used in studies investigating the effects of oestrogen and progesterone on different aspects of exercise performance $[18,47]$. This began to raise an awareness of some of the technical flaws and issues within this field. Cable and Elliott [47] focussed on the methodological approach used in studies investigating the effects of ovarian steroids on muscle strength in women. They identified inconsistencies in terminology and research design, namely differences in the definition of reproductive status (e.g., inconsistencies in menstrual cycle phase definition), often leading to the grouping of non-homogeneous participants; and quantification of reproductive status, by using inaccurate and subjective methods. In addition, they highlighted that consideration needed to be given to characteristics of the hormonal milieu; such as, if the changes in ovarian steroids were acute (e.g., menstrual cycle) or chronic (e.g., menopause); within normal (e.g., menstrual cycle) or supra-physiological (e.g., pregnancy) ranges; caused by endogenous fluctuations (e.g., menstrual cycle) or exogenous (e.g., HC or hormone replacement therapy [HRT]) supplementation. The review by Janse de Jonge [18] focussed on methodological considerations in menstrual cycle research, including the verification of menstrual cycle phase and the timing of testing throughout the cycle. More recently, Janse de Jonge et al. [48] consolidated the approaches and issues observed specifically in menstrual-cycle studies and proposed methodological guidelines for undertaking menstrual cycle-based research in sport and exercise science. Furthermore, broad methodological considerations for studies in exercise endocrinology have been provided lately [49], including the critical consideration of sex and the menstrual cycle. The current statement builds upon these reviews by providing guidance for studies including women from across the lifespan.

\subsection{Approach to the Statement}

The considerations outlined herein are based on previous research and expert opinion and are delivered alongside the rationale and pros and cons for each method. Where appropriate the primary source has been provided; however, some items have been specifically developed for this statement. For ease of reading we are using oestrogen throughout the paper, but recognise this encompasses oestradiol, oestrone and oestriol. For more detailed information on female endocrinology see Hackney [21].

\subsection{Purpose of the Statement}

The aim of this statement was to consolidate the opinions, lessons and evidence from experienced researchers in the area of women's physiology, with a view to providing counsel for those beginning to pursue research in this very important area. Moreover, the considerations described herein are intended to help dispel the myths and poor practices commonly associated with this subject area, thus improving the quality of future research and allowing more meaningful comparisons to be made between studies that have employed consistent terminology and research designs. Overall, this statement aims to contribute to advancing the scientific community's knowledge and understanding of women's physiology in the context of sport and exercise science.

\section{Considerations}

\subsection{Participants}

Much of the heterogeneity in this area of research is derived from the lack of uniformity when describing the populations used in studies with women as participants. While chronological age is often controlled and reported, maturation status and menstrual-cycle status (i.e., length, irregularities/dysfunction, manipulation) are more often not. Moreover, if menstrual-cycle status is even considered by researchers, the hormonal profile of the participants is often implied rather than confirmed [25] which may exacerbate the variability between studies.

In order to overcome these issues, consistency is needed in the following: (i) the terminology used to describe participants; and (ii) the inclusion/exclusion criteria, specifically the hormonal parameters, used to define eligible participants. This uniformity will allow meaningful comparison within and among studies (i.e., comparing like with like). Table 1 proposes a framework of terms and conditions, based on previous research and our collective experience and expertise in the field that could help to ensure consistency in women's sport and exercisebased studies. Across the lifespan, the ovarian steroids start changing at puberty. Therefore, the stage of puberty needs to be classified consistently in research with younger populations. During the reproductive years there are five main factors that will influence the fluctuations in oestrogen and progesterone: i) fluctuations across the eumenorrheic menstrual cycle; ii) disruptions to the eumenorrheic menstrual cycle caused by illness or disease (e.g., polycystic ovary syndrome, endometriosis or other hypothalamic pituitary axis disruptions), low energy availability, the first two years after menses, and the time nearing menopause; iii) manipulation of the eumenorrheic menstrual cycle with exogenous hormones, both synthetic and natural (e.g., $\mathrm{HC}$ and HRT); iv) pregnancy (increasing ovarian steroids profile); and v) menopause (decreasing ovarian steroids 
profile). Researchers should strive to adopt all recommendations that are appropriate, thus facilitating good practice in this area.

\subsection{Experimental Design}

The experimental design employed in studies with women as participants is often poorly considered, described, controlled and/or executed, which is mainly due to a lack of understanding of the hormonal changes experienced across the lifespan in women. In addition, studies involving women as participants usually require repeated measures due to the acute (e.g., ultradian, circadian and infradian rhythms) and chronic fluctuations (e.g., pregnancy, menopause, HC and HRT usage) in reproductive hormones over time, unlike in studies with men as participants who have relatively stable (i.e., outside of circadian variation) sex hormone profiles following puberty. Table 2 outlines some methodological approaches that could be employed at various stages of the life cycle (i.e., puberty, menstrual cycle and irregularities, hormonal contraception, pregnancy and menopause) in women.

One particular aspect of research design that has continued to cause debate amongst authors and disparity between studies is the nomenclature associated with the phases of the menstrual cycle and menopausal status [57]. In the simplest terms, the menstrual cycle can be divided into two phases that are separated by ovulation; follicular (begins at the onset of menses) and luteal (post ovulation). These phases can be further divided into the early, mid and late phases for each, with or without the inclusion of ovulation as a discrete phase. As such, studies involving eumenorrheic women report phases on a continuum from two to seven. Furthermore, the basis for this taxonomy is often unclear; i.e., the phases are linked to poorly defined or undefined ovarian steroid profiles. Rather than continue to dispute the name of menstrual cycle phases, a consensus is needed on the hormonal profiles of interest, such that testing timepoints and the determination of eligible data can be based on an a priori decision. Table 3 and Fig. 4 show four distinct hormonal profiles, which represent significant changes in both oestrogen and progesterone concentrations. These four profiles could be used to investigate the effects of ovarian steroids on physiology, health and performance.

\subsection{General Guidance}

Some methodological issues can affect all sport and exercise science studies with women as participants; these points are described in Table 4. One consideration is the use of "unclassified" women, viz. where the reproductive profile of the participants is not stated. In some studies, it is relevant to describe the menstrual characteristics of the participants, but not necessary to measure ovarian steroid levels. It is important to balance the internal and external validity of a study, such that the translational reach and impact of the data are not limited. The research design should be suitable to answer the research question. For example, if a study is designed to examine the effects of menstrual cycle phase on an outcome, then biochemical confirmation of the phase is warranted alongside self-reported menstrual characteristics (e.g., last menses), whereas if a study is designed to examine the physical/performance characteristics of a female sports team, then a description of the population (i.e., solely selfreported menstrual cycle phase) may be sufficient. As such, the research question should clearly indicate if the intention is to attribute an outcome to a specific hormonal profile or to observe the characteristics/responses of a clearly defined, mixed group of sportswomen or exercisers.

\section{Discussion}

\subsection{Definition of 'Woman'}

Herein cisgender females are described and defined based on ovarian steroid concentrations. Transgender females and women with differences in sexual development have not been characterised but require and deserve further clear research parameters to better understand their physiology. The diversity in female reproductive endocrinology makes it difficult to title and define women based on reproductive hormonal profile alone. As such, it can be challenging for researchers to decide on the inclusion/exclusion criteria for participant recruitment; determine the methods by which this criteria can be established; and use the eligibility criteria to inform the research design.

- Example 1; a researcher wishing to investigate potential effects of the menstrual cycle on exercise performance needs to decide: if they will use eumenorrheic or naturally menstruating women (see Table 1 for delineation of terminology); how they will confirm eumenorrhea; when in the cycle they will test to ensure different hormonal environments.

- Example 2; a researcher wishing to use oral contraceptive pill (OCP) users will need to decide which role they will fulfil (i.e., control or experimental sample [56]):

- OCP users can be used as a control group, wherein cyclical fluctuations in oestrogen and progesterone experienced during the menstrual cycle can be compared to consistently downregulated sex hormone levels. The researcher then needs to decide whether to compare with the active pill phase or the non-active pill phase. For example, if the non-active pill phase is compared with the early follicular phase, then it is likely that the 


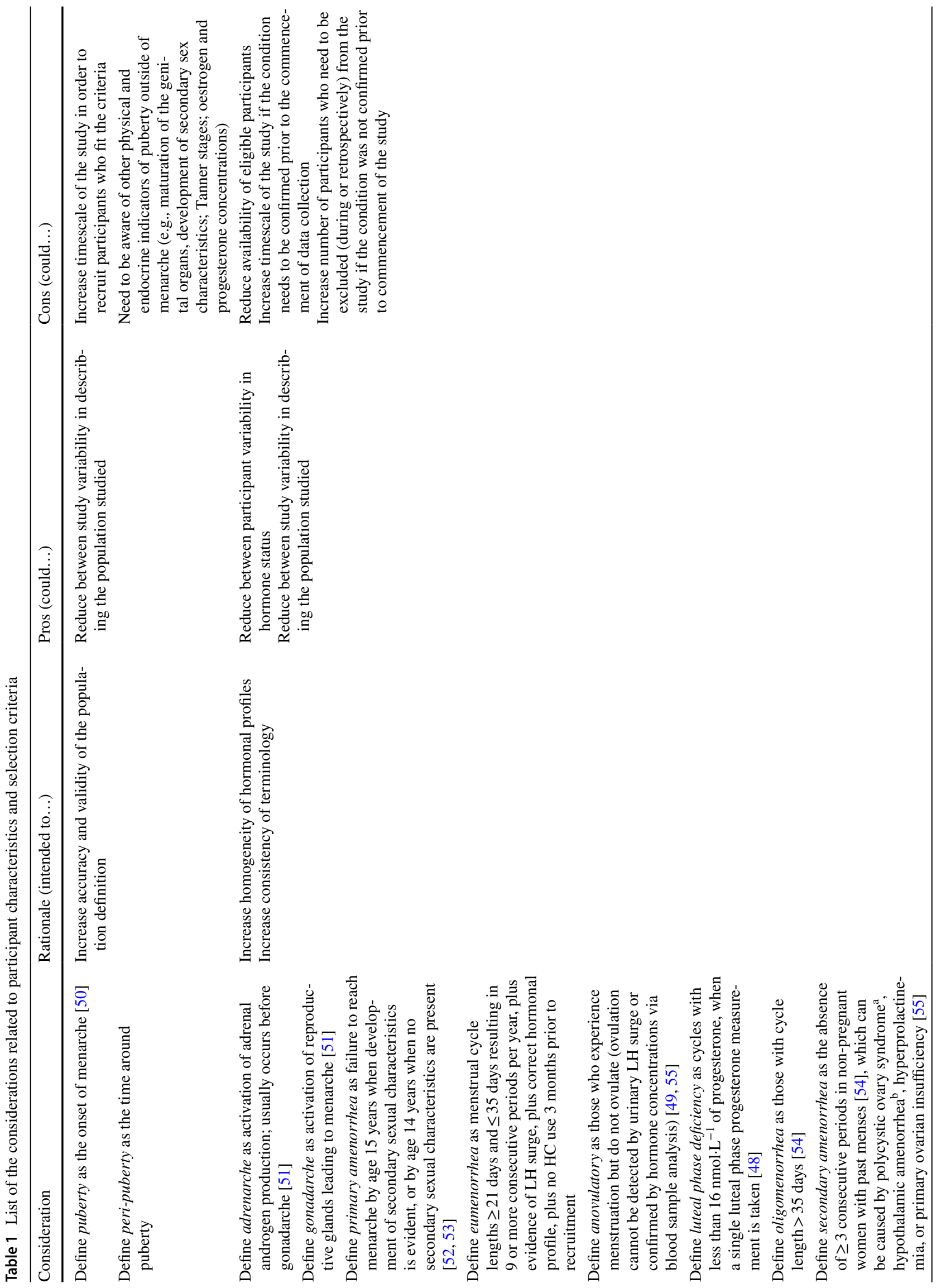




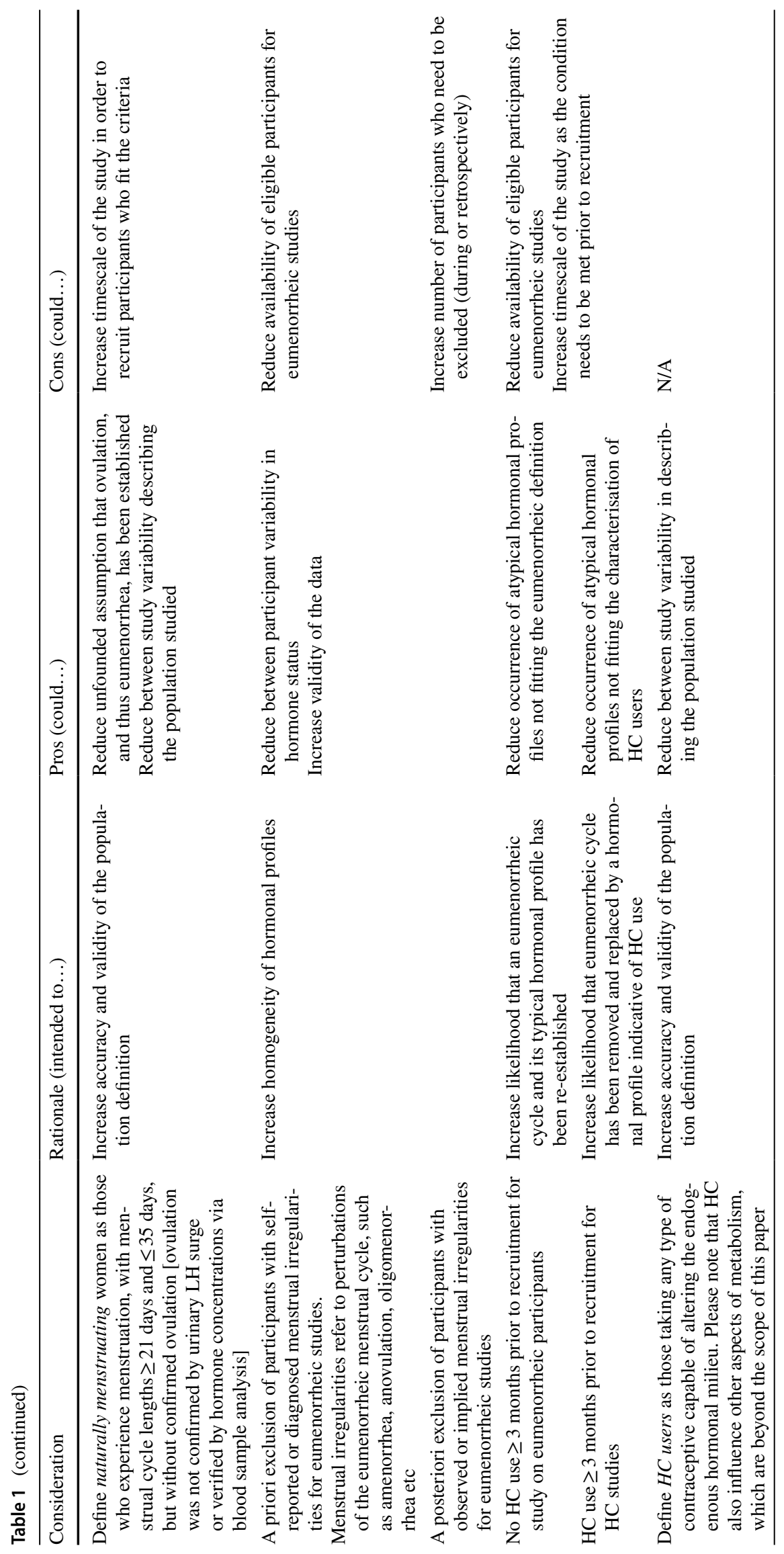




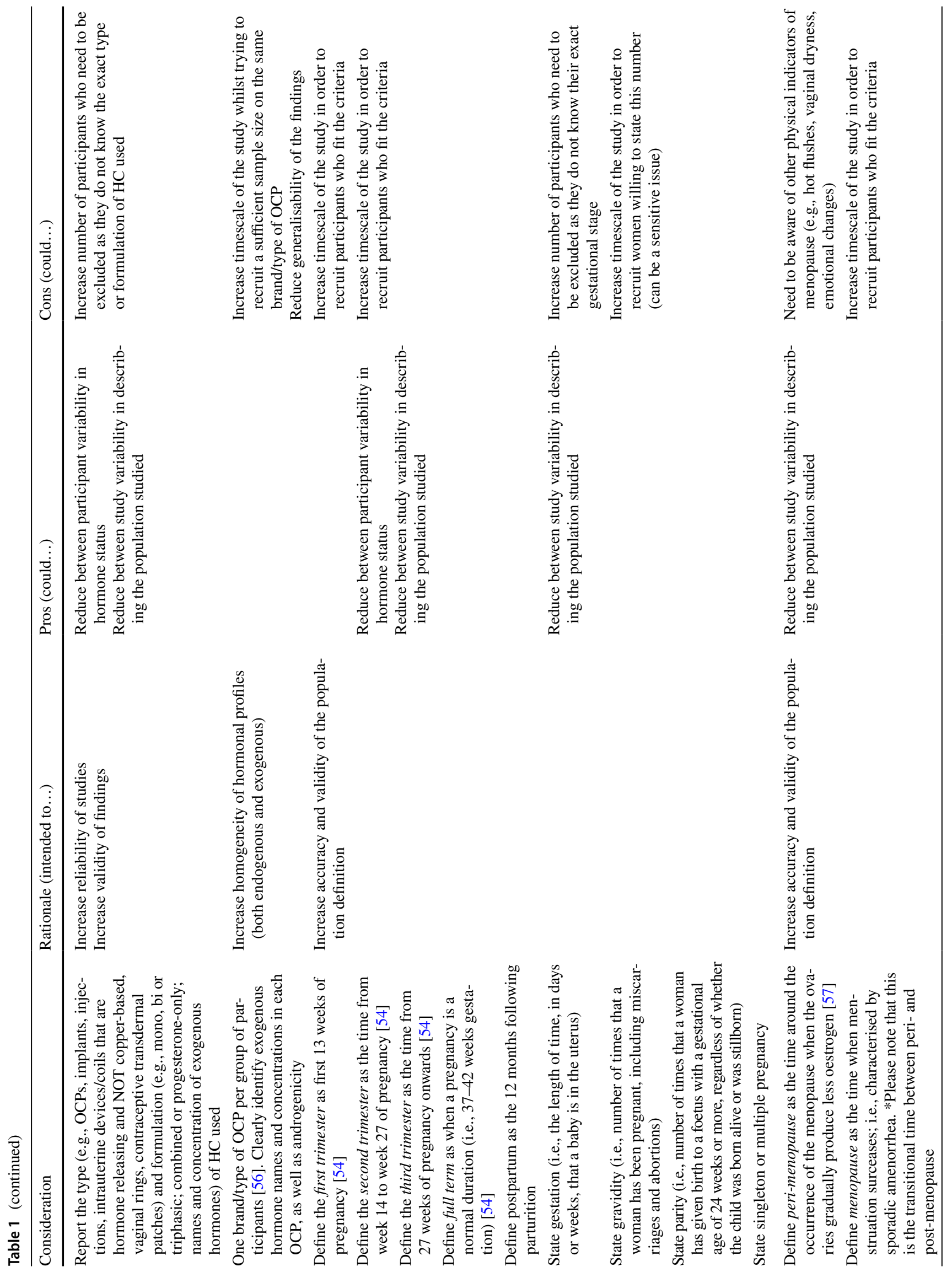




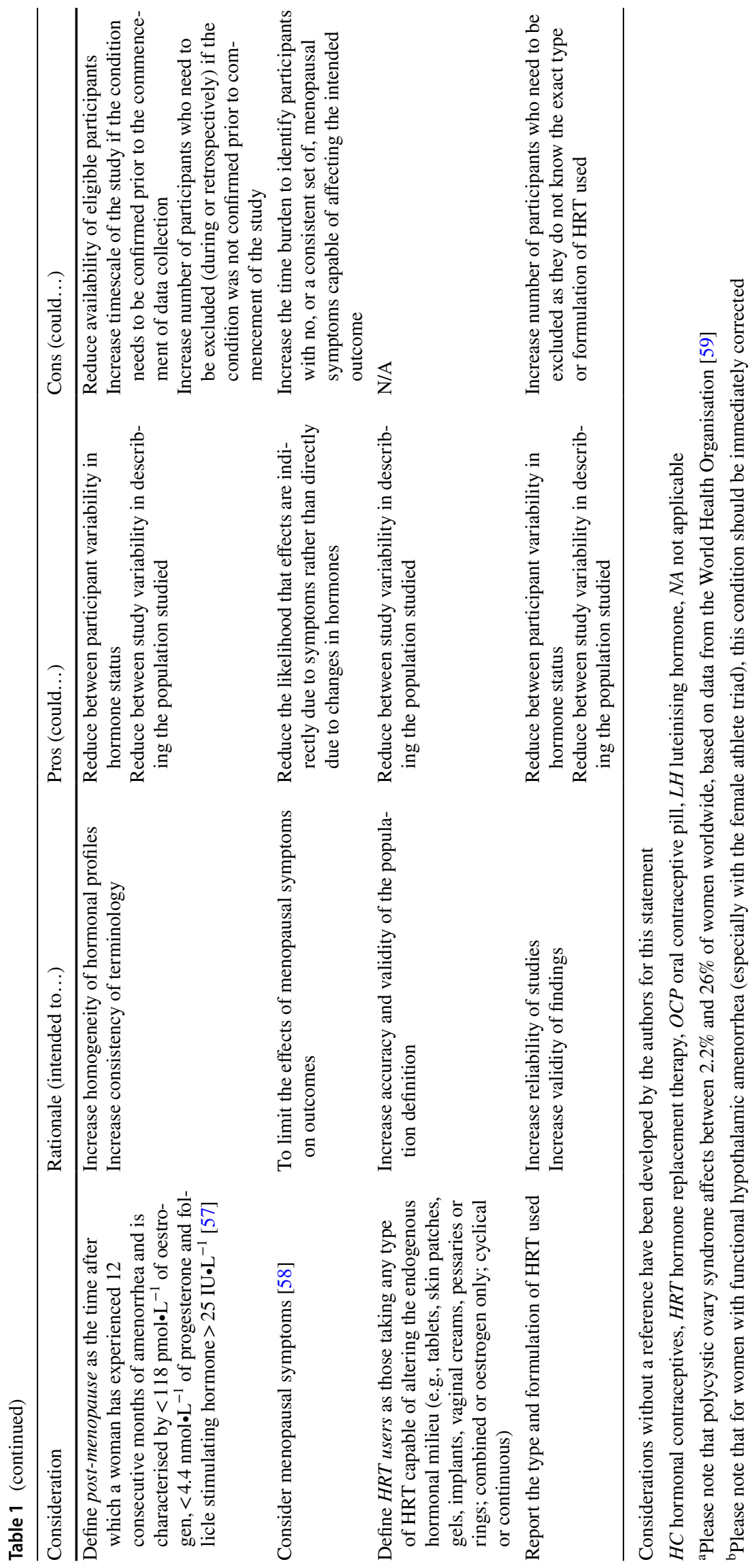




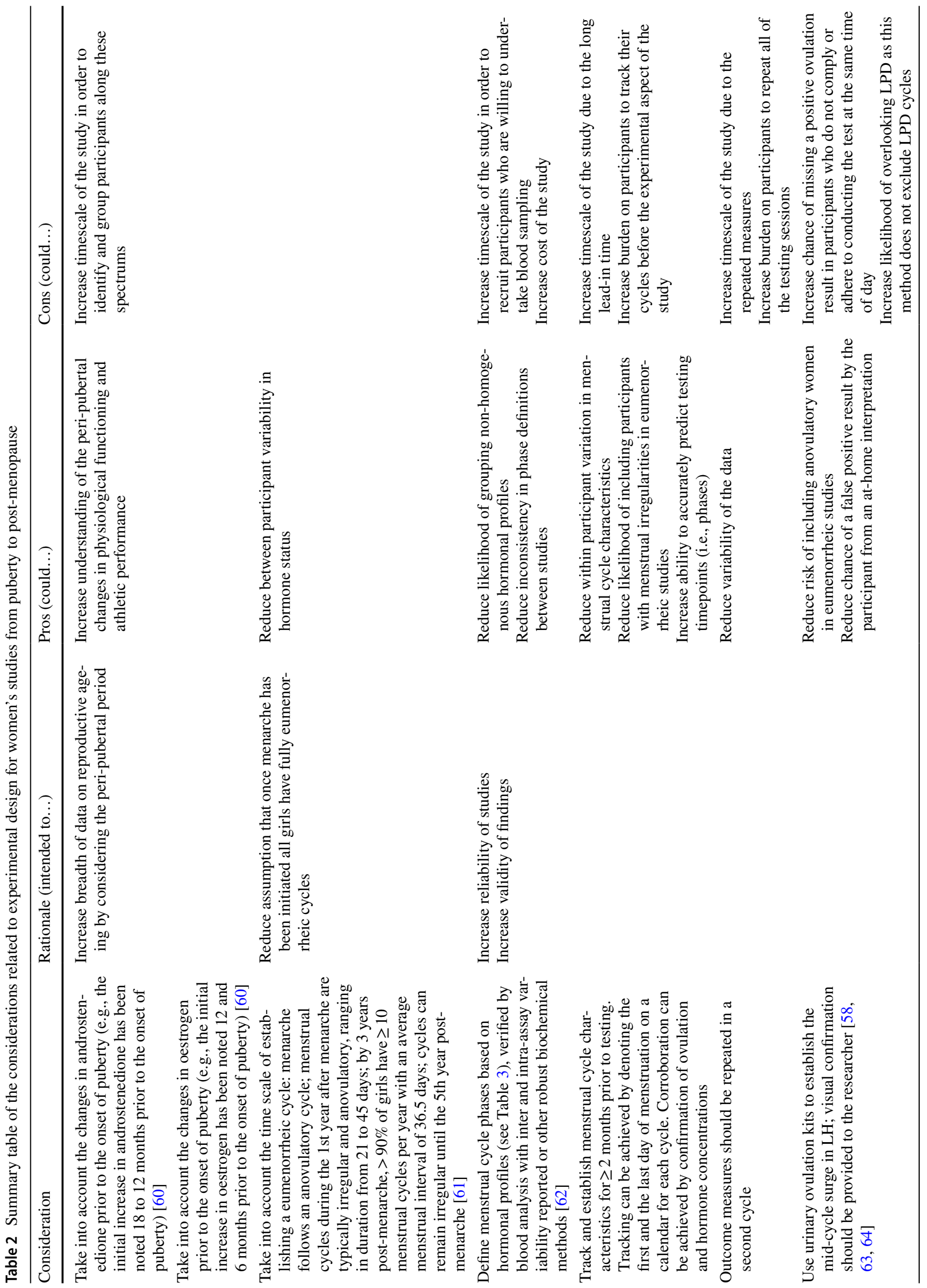




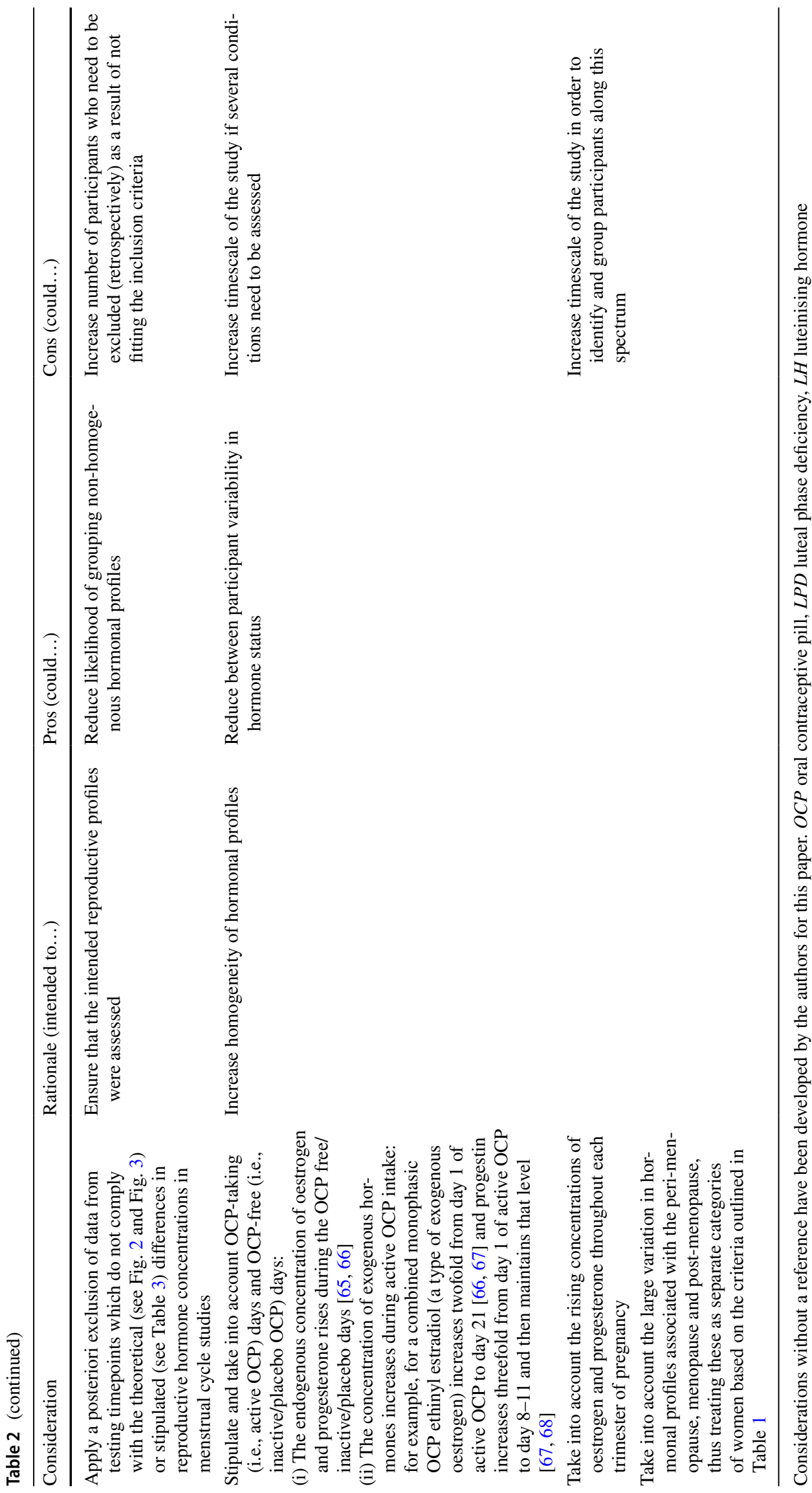




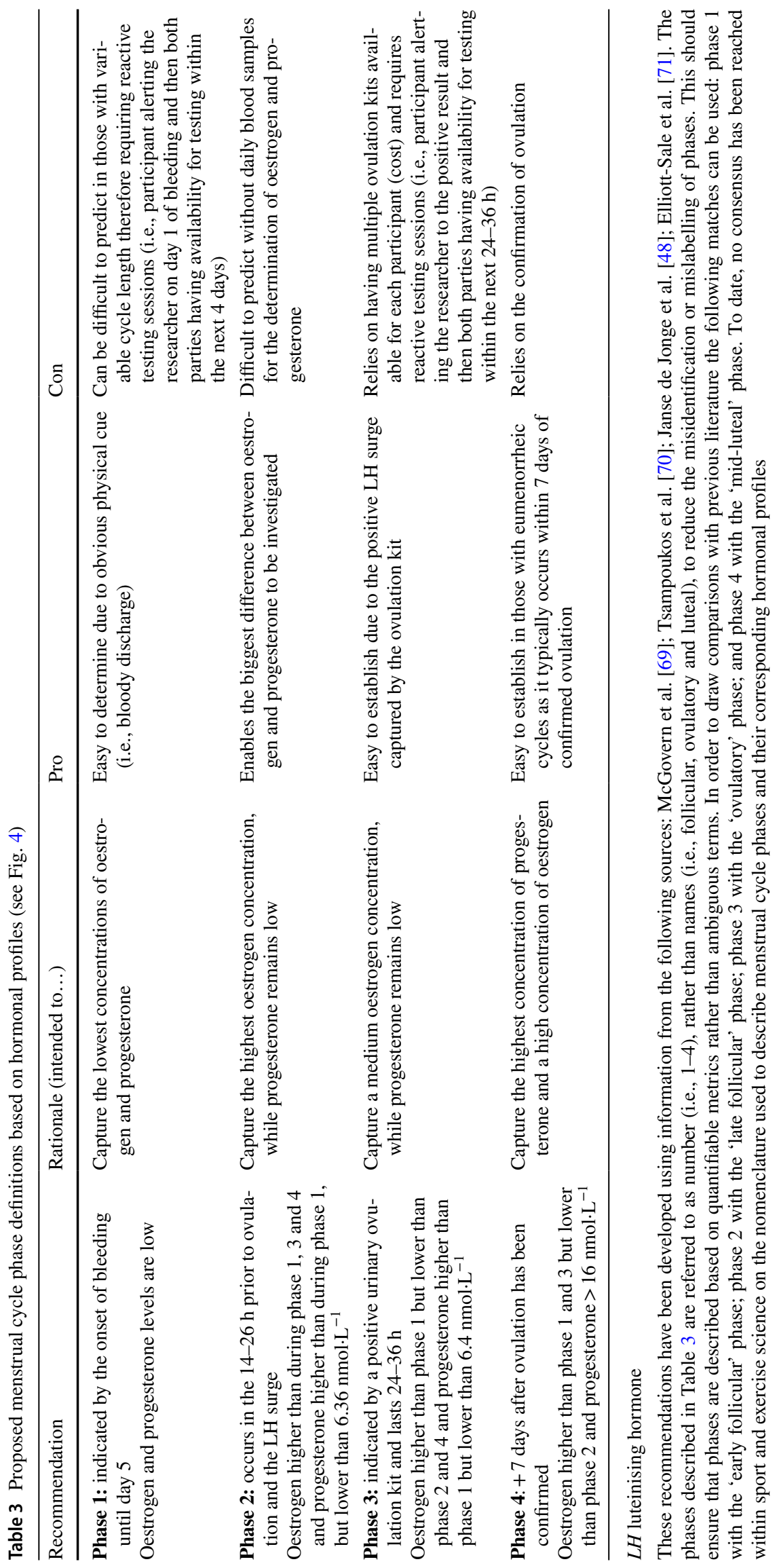




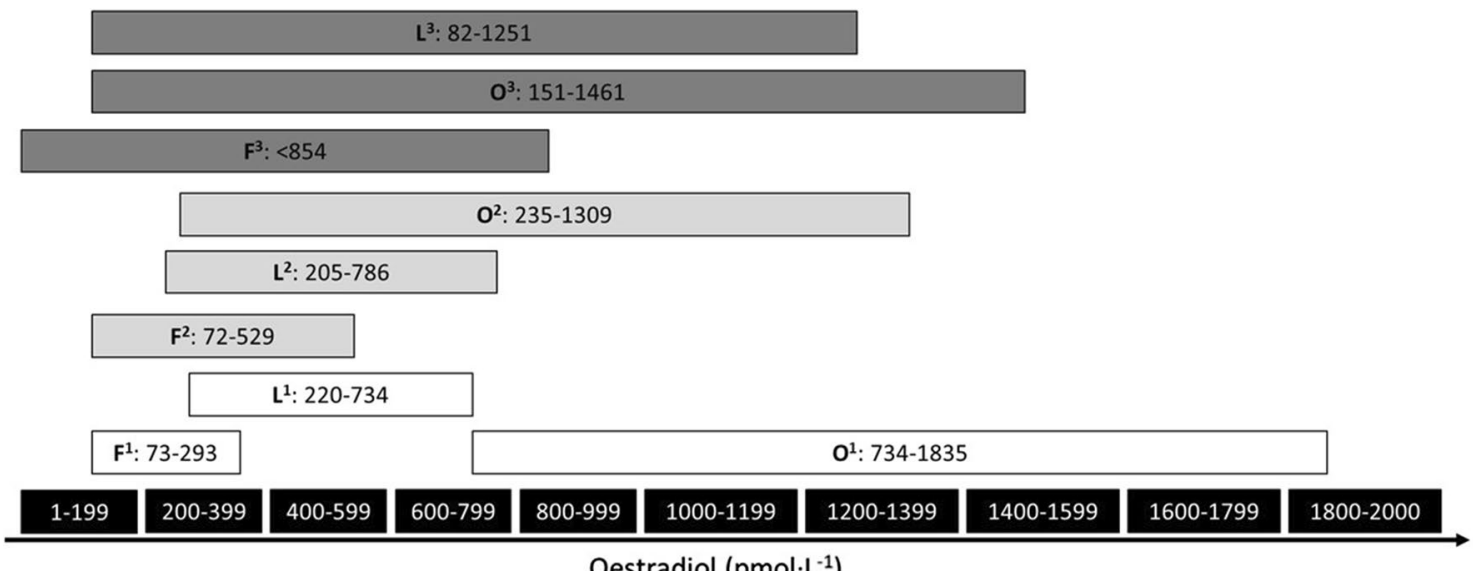

Fig. 2 Oestrogen reference ranges from three different sources ${ }^{1,2,3}$ for the follicular $(\mathrm{F})$, ovulatory $(\mathrm{O})$ and luteal $(\mathrm{L})$ phases of the menstrual cycle. All sources are clinical reference ranges from different National Health Service Trusts in the UK and are based on the manufacturers' laboratory reference ranges. This figure illustrates the differences in the reference ranges for each of the three prevailing oestrogen phases of the eumenorrheic menstrual cycle and suggests that additional context is required (e.g., blood sample taken on day two of bleeding, thus allowing the comparison with the follicular range; blood sample taken $12 \mathrm{~h}$ after ovulation was denoted by a positive urinary luteinising hormone test kit, thus allowing comparison with the ovulatory range; blood sample taken seven days after ovulation was denoted by a positive urinary luteinising hormone test kit, thus allowing comparison with the luteal range values)

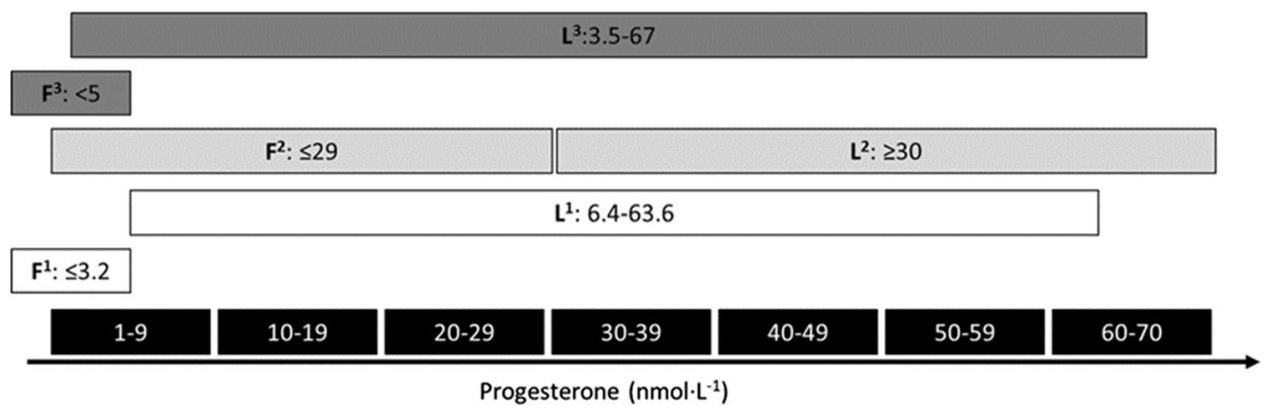

Fig. 3 Progesterone reference ranges from three different sources ${ }^{1,2,3}$ for the follicular $(\mathrm{F})$ and luteal $(\mathrm{L})$ phases of the menstrual cycle. All sources are clinical reference ranges from different National Health Service Trusts in the UK and are based on the manufacturers' laboratory reference ranges. This figure illustrates the differences in the reference ranges for each of the two prevailing progesterone phases of the eumenorrheic menstrual cycle and suggests that additional context is required (e.g., blood sample taken on day two of bleeding, thus allowing the comparison with the follicular range; blood sample taken seven days after ovulation was denoted by a positive urinary luteinising hormone test kit, thus allowing comparison with the luteal range values)

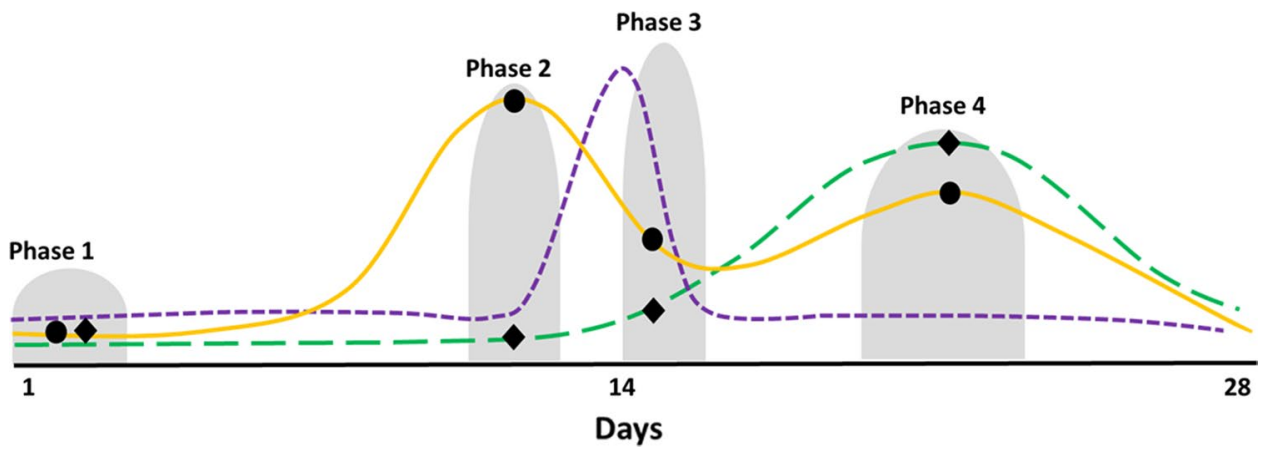

Fig. 4 Visual overlay of the hormonal changes across an idealised 28-day menstrual cycle indicating when each phase begins and ends as described in Table 3 . The solid gold line represents oestrogen the short dash purple line represents luteinising hormone and the long dash green line represents progesterone. The black dots represent the mean concentration of oestrogen during each phase and the black diamonds represent the mean concentration of progesterone in each phase 


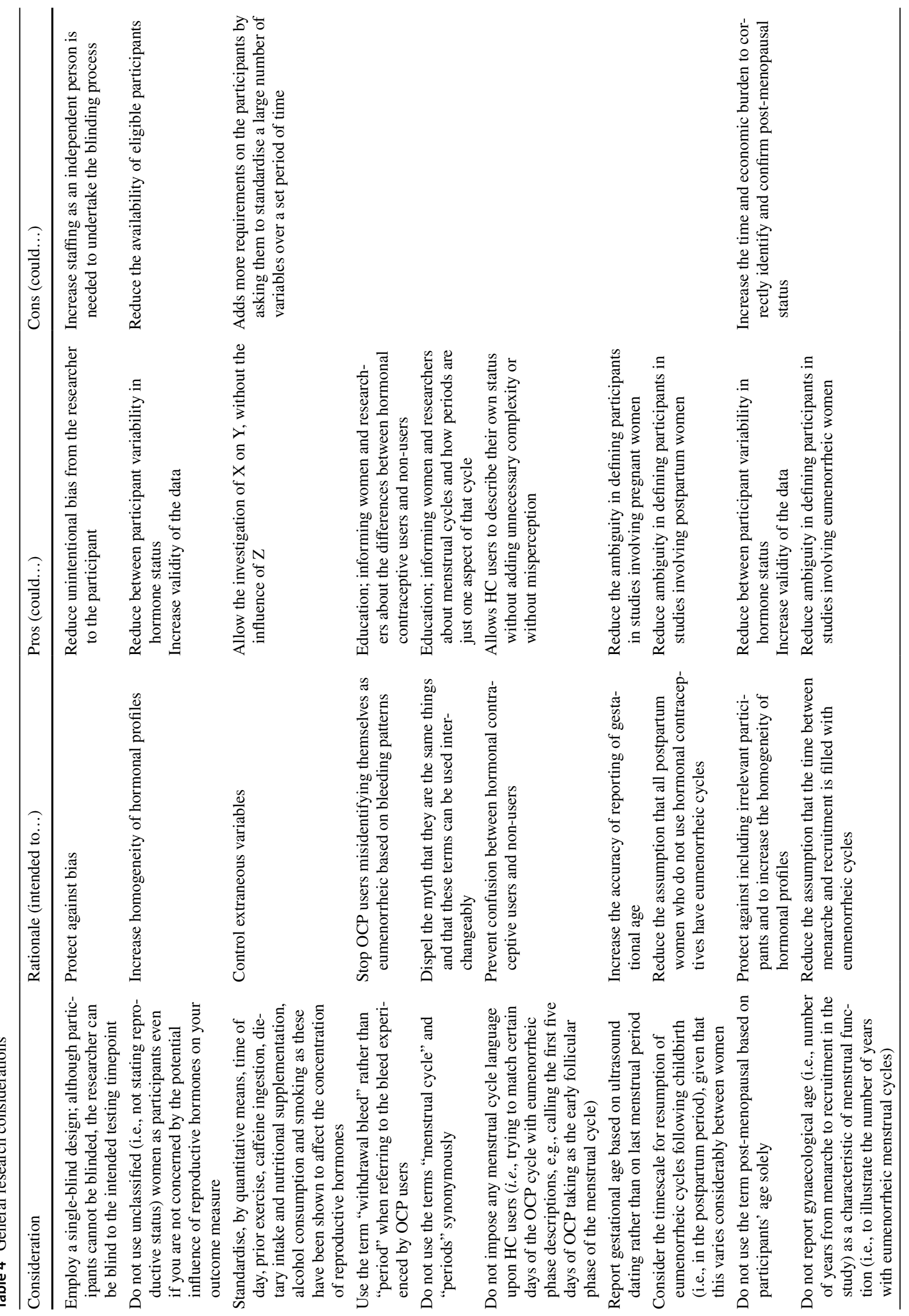


hormonal environments will be very similar between the two groups. If the mid-luteal phase is compared with the active pill phase, the hormonal environments between groups will be different. The researcher will also need to consider the type of OCP being used (i.e., oestrogen and progestin formulations and concentrations; monophasic, biphasic, triphasic) and the duration of usage, ensuring this is similar for the whole control group of OCP users.

- OCP users can also be considered as an experimental group, wherein (i) the effects of low endogenous oestrogen and progesterone levels can be investigated and/ or (ii) the effects of exogenous oestrogen and progestin can be examined. In this case the researcher needs to decide which hormonal environments to compare, early in the non-active pill phase (with low endogenous and exogenous hormone levels), late in the non-active pill phase (with increasing endogenous oestrogen and low exogenous hormones), early in the active pill phase (with increasing exogenous hormone levels) or late in the active pill phase (with highest exogenous hormone levels). Again, the researcher will need to consider the type of OCP being used and ensure this is similar for the whole control group of OCP users and/or consider comparison between different types of OCP.

Example 3; a researcher wishing to conduct menopauserelated study needs to decide which menopausal phases to include and how to define those phases; whether or not to include HRT users or those with ovarian concerns that have resulted in hormonal conditions similar to menopause; if post-menopausal women are included, how to define the time that the participants have been post-menopausal [72].

As such, we propose that:

(i) sample populations are chosen based on the research question;

(ii) participants are clearly named and described based on their reproductive characteristics;

(iii) hormonal profiles are used to inform the experimental design.

These steps should help alleviate the ambiguity surrounding the classification of women previously seen in sport and exercise studies that has led to considerable sampling heterogeneity and has hindered meaningful comparison between studies.

\subsection{Study Validity}

The validity of studies, or lack thereof, in sport and exercise science using women as participants is rarely discussed. The considerations described herein are designed to increase the internal validity through adequate quality control as a result 
of stringent recruitment strategies (e.g., using predetermined population definitions and strict inclusion/exclusion criteria) and appropriate experimental design (e.g., a priori classification of hormonal profile associated with each testing timepoint and post priori exclusion of data not meeting the stipulated terms). These measures should help to ensure that the results reflect the truth in the population studied rather than methodological errors [73]. At present, given the lack of clarity on either the direction or magnitude of potential effects of ovarian steroids on physical performance, maximising internal validity should be considered a research priority. The external validity of studies involving women as participants is often more difficult to increase due to the large inter and intra-individual variability in ovarian hormone concentrations; by reducing some of this variation through precise recruitment and testing, the external validity is lessened, and thus generalisability is reduced. These issues can be somewhat overcome through field-based testing and by testing entire teams, which could help maximise the translational potential of performance-based research in women.

\subsection{Inclusion of Research with Women as Participants}

Until recently, women were less represented in elite sport. Women accounted for only $2.2 \%$ of the athletes in the Paris Olympics in 1900 , but they are predicted to account for an estimated high of $48.8 \%$ in the next Olympic Games [74]. Therefore, the time is right to shift more attention to women as participants in sport and exercise science research, especially given that often the research findings that are based on male participants are neither applicable nor generalizable to women. It is not appropriate to exclude women from sport and exercise science research for any reason, especially on the basis of convenience, i.e. excluding women as participants due to the potential confounding effect of female hormone fluctuations, or cost, i.e., excluding women as participants because they can be more expensive than men to study due to the extra time (e.g., repeated measures across a menstrual cycle) and resources (e.g., blood samples for the determination of ovarian steroid levels) needed to produce high-quality data. Unfortunately, it is evident that many researchers have avoided using female participants with data indicating just 4 to $13 \%$ of articles from leading journals in sports and exercise science included only women as participants [15]. So even though some research has focussed on the effects of ovarian steroids on performance, health and physiology, the small quantity of research in this area limits our understanding of the topic. Furthermore, the heterogeneity in study populations (e.g., eumenorrheic, OCP user, post-menopausal) and large variation in research designs (e.g., definition of menstrual cycle phase, oral contraceptive pill consumption or withdrawal) has resulted in many conflicting findings in sport and exercise science research with women as participants. To improve our understanding of many female specific topics, undoubtedly more high-quality research is warranted to overcome the heterogeneity and ambiguity seen in the limited number of studies in this area to date. Women account for half the world-wide population, therefore a willingness to study women as participants in sport and exercise science needs to be fostered and funding needs to be made available to achieve equivalence in knowledge about the female sex.

\subsection{Limitations of the Statement}

Although this paper has covered many aspects of the reproductive ageing female (i.e., from puberty to the menopause), it has not covered every perturbation of the menstrual cycle [75] or every type of hormonal contraceptive [76] or all aspects of (post) menopausal hormonal therapy. In addition, medications known to influence the hypothalamic-pituitaryovarian axis are beyond the scope of this statement [77].

\section{Conclusions}

In order to improve the quality of future research in sport and exercise science with women as participants, more researchers need to accept the challenges of working in this area and embrace the means and mechanisms to produce high quality scientific studies on essentially half the world's population. The considerations presented in this paper are not intended to be the panacea for studies on sportswomen; instead they are intended to guide readers to adopt good practice in this area and prompt further consideration of the issues involved in women-based sport and exercise science studies. As every woman's menstrual cycle is different and can change across the lifespan, there might never be a universal blueprint that research studies and practitioners can exclusively use to direct training and performance; however, if we understand and appreciate how ovarian hormones affect different physiological systems, we can use this knowledge to tailor exercise programmes for women in response to the reproductive events throughout their lifespan.

\section{Declarations}

Funding No funding was received for this work.

Conflicts of interest Kirsty Elliott-Sale, Clare Minahan, Xanne Janse de Jonge, Kathryn Ackerman, Sarianna Sipilä, Naama Constantini, Constance Lebrun and Anthony Hackney declare that they have no conflicts of interest relevant to the content of this article.

Ethics approval Not applicable. 
Consent to participate Not applicable.

Consent for publication Not applicable.

Availability of data and material Not applicable.

Code availability Not applicable.

Author contributions KES wrote the first draft of the manuscript. $\mathrm{ACH}, \mathrm{CLM}$ and XAKJDJ revised the original manuscript. SS added content regarding the menopause; KEA added content regarding endocrine profiles; CML added content regarding the menstrual cycle and hormonal contraceptives; NWC added content regarding the application and scope of the work. All authors read and approved the final manuscript.

Open Access This article is licensed under a Creative Commons Attribution 4.0 International License, which permits use, sharing, adaptation, distribution and reproduction in any medium or format, as long as you give appropriate credit to the original author(s) and the source, provide a link to the Creative Commons licence, and indicate if changes were made. The images or other third party material in this article are included in the article's Creative Commons licence, unless indicated otherwise in a credit line to the material. If material is not included in the article's Creative Commons licence and your intended use is not permitted by statutory regulation or exceeds the permitted use, you will need to obtain permission directly from the copyright holder. To view a copy of this licence, visit http://creativecommons.org/licenses/by/4.0/.

\section{References}

1. Insler V, Melmed H, Mashiah S, Monselise M, Lunenfeld B, Rabau E. Functional classification of patients selected for gonadotropic therapy. Obstet Gynecol. 1968;32(5):620-6.

2. Collins BC, Arpke RW, Larson AA, Baumann CW, Xie N, Cabelka CA, et al. Estrogen regulates the satellite cell compartment in females. Cell Rep. 2019;28(2):368-381.e6.

3. Sipilä S, Finni T, Kovanen V. Estrogen influences on neuromuscular function in post-menopausal women. Calcif Tissue Int. 2015;96(3):222-33.

4. Wierman ME. Sex steroid effects at target tissues: mechanisms of action. Adv Physiol Educ. 2007;31(1):26-33.

5. Wiik A, Ekman M, Johansson O, Jansson E, Esbjornsson M. Expression of both oestrogen receptor alpha and beta in human skeletal muscle tissue. Histochem Cell Biol. 2009;131:181-9.

6. Hackney AC, McCracken-Compton MA, Ainsworth B. Substrate responses to submaximal exercise in the midfollicular and midluteal phases of the menstrual cycle. Int J Sport Nutr. 1994;4(3):299-308.

7. Birch K, Reilly $\mathrm{T}$. The diurnal rhythm in isometric muscular performance differs with eumenorrheic menstrual cycle phase. Chronobiol Int. 2002;19(4):731-42.

8. Savage KJ, Clarkson PM. Oral contraceptive use and exercise-induced muscle damage and recovery. Contraception. 2002;66(1):67-71.

9. Isacco L, Duché P, Boisseau N. Influence of hormonal status on substrate utilization at rest and during exercise in the female population. Sports Med. 2012;42(4):327-42.

10. Macnutt MJ, De Souza MJ, Tomczak SE, Homer JL, Sheel AW. Resting and exercise ventilatory chemosensitivity across the menstrual cycle. J Appl Physiol. 2012;112(5):737-47.
11. Boss L, Kang DH, Marcus M, Bergstrom N. Endogenous sex hormones and cognitive function in older adults: a systematic review. West J Nurs Res. 2014;36(3):388-426.

12. Herzberg SD, Motu'apuaka ML, Lambert W, Fu R, Brady J, Guise JM. The effect of menstrual cycle and contraceptives on ACL injuries and laxity: a systematic review and meta-analysis. Orthop J Sports Med. 2017;5(7):2325967117718781.

13. Minahan C, O'Neill H, Sikkema N, Joyce S, Larsen B, Sabapathy $\mathrm{S}$. Oral contraceptives augment the exercise pressor reflex during isometric handgrip exercise. Physiol Rep. 2018;6(5):e13629.

14. Jacobi M. The question of rest for women during menstruation. New York: G.P. Putnam's sons; 1877.

15. Costello JT, Bieuzen F, Bleakley CM. Where are all the female participants in Sports and Exercise Medicine research? Eur J Sport Sci. 2014;14(8):847-51.

16. Lebrun CM. Effect of the different phases of the menstrual cycle and oral contraceptives on athletic performance. Sports Med. 1993;16(6):400-30.

17. Frankovich RJ, Lebrun CM. Menstrual cycle, contraception, and performance. Clin Sports Med. 2000;19(2):251-71.

18. Janse de Jonge XAK. Effects of the menstrual cycle on exercise performance. Sports Med. 2003;33 (11):833-851.

19. Constantini NW, Dubnov G, Lebrun CM. The menstrual cycle and sport performance. Clin Sports Med. 2005;24(2):e51-xiv.

20. Thompson B, Almarjawi A, Sculley D. Janse de Jonge X. The effect of the menstrual cycle and oral contraceptives on acute responses and chronic adaptations to resistance training: A systematic review of the literature. Sports Med. 2020;50(1):171-85.

21. Hackney AC, editor. Sex hormones, exercise and women; scientific and clinical aspects. Switzerland: Springer; 2017.

22. Forsyth J, Roberts CM, editors. The exercising female science and its application. London: Routledge; 2018.

23. Hackney AC, Constantini N, editors. Endocrinology of physical activity in sport. 3rd ed. Switzerland: Humana; 2020.

24. Elliott-Sale KJ, McNulty KL, Ansdell P, Goodall S, Hicks KM, Thomas K, et al. The effects of oral contraceptives on exercise performance in females: a systematic review and meta-analysis. Sports Med. 2020;50(10):1785-812.

25. McNulty KL, Elliott-Sale KJ, Dolan E, Swinton PA, Ansdell P, Goodall S, et al. The effects of menstrual cycle phase on exercise performance in eumenorrheic women: a systematic review and meta-analysis. Sports Med. 2020;50(10):1813-27.

26. Carter A, Dobridge J, Hackney A. Infuence of estrogen on markers of muscle tissue damage following eccentric exercise. Hum Physiol. 2001;27:626-30.

27. Joyce S, Sabapathy S, Bulmer AC, Minahan C. The effect of prior eccentric exercise on heavy-intensity cycling: the role of gender and oral contraceptives. Eur J Appl Physiol. 2014;114:1-9.

28. Minahan C, Joyce S, Bulmer AC, Cronin N, Sabapathy $\mathrm{S}$. The influence of estradiol on muscle damage and leg strength after intense eccentric exercise. Eur J Appl Physiol. 2015;115(7):1493-500.

29. Hicks KM, Onambélé-Pearson G, Winwood K, Morse CI. Oral contraceptive pill use and the susceptibility to markers of exerciseinduced muscle damage. Eur J Appl Physiol. 2017;117:1393-402.

30. Mackay K, González C, Zbinden-Foncea H, Peñailillo L. Effects of oral contraceptive use on female sexual salivary hormones and indirect markers of muscle damage following eccentric cycling in women. Eur J Appl Physiol. 2019;119:2733-44.

31. Rogers SM, Baker MA. Thermoregulation during exercise in women who are taking oral contraceptives. Eur J Appl Physiol Occup Physiol. 1997;75(1):34-8. 
32. Tenaglia SA, McLellan TM, Klentrou PP. Infuence of menstrual cycle and oral contraceptives on tolerance to uncompensable heat stress. Eur J Appl Physiol Occup Physiol. 1999;80:76-83.

33. Stachenfeld NS, Silva C, Keefe DL. Estrogen modifes the temperature effects of progesterone. J Appl Physiol. 2000;88:1643-9.

34. Minahan C, Melnikoff M, Quinn K, Larsen B. Response of women using oral contraception to exercise in the heat. Eur J Appl Physiol. 2017;117(7):1383-91.

35. Lebrun CM, Joyce SM, Constantini NW. Effects of Female Reproductive Hormones on Sports Performance. In: Hackney A, Constantini N, editors. Endocrinology of Physical Activity and Sport. Contemporary Endocrinology. Switzerland: Humana; 2020.

36. D'Eon TM, Sharoff C, Chipkin SR, Grow D, Ruby BC, Braun B. Regulation of exercise carbohydrate metabolism by estrogen and progesterone in women. Am J Physiol Endocrinol Metab. 2002;283:E1046-55.

37. Tarnopolsky MA. Sex differences in exercise metabolism and the role of 17-beta estradiol. Med Sci Sports Exerc. 2008;40:648-54.

38. Oosthuyse T, Bosch AN. The effect of the menstrual cycle on exercise metabolism: implications for exercise performance in eumenorrhoeic women. Sports Med. 2010;40:207-27.

39. Daily JP, Stumbo JR. Female athlete triad. Prim Care. 2018;45(4):615-24.

40. Metcalf BS, Hosking J, Jeffery AN, Henley WE, Wilkin TJ. Exploring the adolescent fall in physical activity: a 10-yr cohort study (early bird 41). Med Sci Sports Exerc. 2015;47(10):2084-92.

41. Dumith SC, Gigante DP, Domingues MR, Kohl HW 3rd. Physical activity change during adolescence: a systematic review and a pooled analysis. Int J Epidemiol. 2011;40(3):685-98.

42. Active lives survey: https://www.sportengland.org/know-youraudience/data/active-lives

43. Sipilä S, Törmäkangas T, Sillanpää E, Aukee P, Kujala U, Kovanen V, et al. Muscle and bone mass in middle-aged women: role of menopausal status and physical activity. J Cachexia Sarcopenia Muscle. 2020;11(3):698-709.

44. Bondarev D, Laakkonen EK, Finni T, Kokko K, Kujala UM, Aukee P, et al. Physical performance in relation to menopausal status and physical activity. Menopause. 2018;25(12):1432-41.

45. Knechtle B, Chlíbková D, Papadopoulou S, Mantzorou M, Rosemann T, Nikolaidis PT. Exercise-associated hyponatremia in endurance and ultra-endurance performance-aspects of sex, race location, ambient temperature, sports discipline, and length of performance: a narrative review. Medicina (Kaunas, Lithuania). 2019;55(9):537.

46. Lei TH, Cotter JD, Schlader ZJ, Stannard SR, Perry BG, Barnes MJ, et al. On exercise thermoregulation in females: interaction of endogenous and exogenous ovarian hormones. J Physiol. 2019;597(1):71-88.

47. Cable NT, Elliott KJ. The influence of reproductive hormones on muscle strength. Biol Rhythm Res. 2004;35:235-44.

48. Janse de Jonge X, Thompson B, Han A. Methodological recommendations for menstrual cycle research in sports and exercise. Med Sci Sports Exerc. 2019;51(12):2610-2617.

49. Hackney AC, Smith-Ryan A, Fink J. Methodological Considerations in Exercise Endocrinology. In: Hackney A, Constantini N, editors. Endocrinology of Physical Activity and Sport. Contemporary Endocrinology. Switzerland: Humana; 2020.

50. Gove PB, editor. Webster's third new international dictionary of the English language, unabridged, Springfield: Mass. Merriam Co: G. \& C; 1961.

51. Witchel SF, Topaloglu AK. Puberty: Gonadarche and Adrenarche. In: Yen and Jaffe's Reproductive Endocrinology: Physiology, Pathophysiology, and Clinical Management. 8th Ed. Philadelphia: Elsevier; 2019.
52. Practice Committee of the American Society for Reproductive Medicine. Current evaluation of amenorrhea. Fertil Steril. 2006;86:S148-55.

53. Schwab SH, Posner JC. Menstrual Disorders. In: Baren JM, Rothrock SG, Brennan JA, Brown L, editors. Pediatric Emergency Medicine. Philadelphia: Elsevier; 2008.

54. Medical dictionary: https://www.merriam-webster.com/medic al

55. Klein DA, Poth MA. Amenorrhea: an approach to diagnosis and management. Am Fam Physician. 2013;87(11):781-8.

56. Elliott-Sale KJ, Smith S, Bacon J, Clayton D, McPhilimey M, Goutianos G, et al. Examining the role of OC users as an experimental and/or control group in athletic performance studies. Contraception. 2013;88(3):408-12.

57. Harlow SD, Gass M, Hall JE, Lobo R, Maki P, Rebar RW, et al.; STRAW + 10 Collaborative Group. Executive summary of the Stages of Reproductive Aging Workshop + 10: addressing the unfinished agenda of staging reproductive aging. J Clin Endocrinol Metab. 2012;97(4):1159-68.

58. Bondarev D, Sipilä S, Finni T, Kujala UM, Aukee P, Laakkonen EK, et al. The role of physical activity in the link between menopausal status and mental well-being. Menopause. 2020;27(4):398-409.

59. Kabel AM. Polycystic ovarian syndrome: insights into pathogenesis, diagnosis, prognosis, pharmacological and non-pharmacological treatment. Pharmacol Rep. 2016;1:E1-5.

60. Biro FM, Pinney SM, Huang B, Baker ER, Walt Chandler D, Dorn LD. Hormone changes in peripubertal girls. J Clin Endocrinol Metab. 2014;99(10):3829-35.

61. Legro RS, Lin HM, Demers LM, Lloyd T. Rapid maturation of the reproductive axis during perimenarche independent of body composition. J Clin Endocrinol Metab. 2000;85:1021-5.

62. Hackney AC, Viru A. Research methodology: endocrinologic measurements in exercise science and sports medicine. J Athl Train. 2008;43(6):631-9.

63. Miller PB, Soules MR. The usefulness of a urinary LH kit for ovulation prediction during menstrual cycles of normal women. Obstet Gynecol. 1996;87(1):13-7.

64. Schaumberg MA, Jenkins DG, Janse de Jonge XAK, Emmerton LM, Skinner TL. Three-step method for menstrual and oral contraceptive cycle verification. J Sci Med Sport. 2017;20(11):965-69.

65. Carol W, Klinger G, Jäger R, Kasch R, Brandstädt A. Pharmacokinetics of ethinylestradiol and levonorgestrel after administration of two oral contraceptive preparations. Exp Clin Endocrinol Diabetes. 1992;99(01):12-7.

66. Spona J, Elstein M, Feichtinger W, Sullivan H, Lüdicke F, Müller $\mathrm{U}$, et al. Shorter pill-free interval in combined oral contraceptives decreases follicular development. Contraception. 1996;54(2):71-7.

67. Blode H, Kowal K, Roth K, Reif S. Pharmacokinetics of drospirenone and ethinylestradiol in Caucasian and Japanese women. Eur J Contracep Reprod Health Care. 2012;17(4):284-97.

68. Endrikat J, Blode H, Gerlinger C, Rosenbaum P, Kuhnz W. A pharmacokinetic study with a low-dose oral contraceptive containing 20 microg ethinylestradiol plus 100 microg levonorgestrel. Eur J Contracep Reprod Health Care. 2002;7(2):79-90.

69. McGovern PG, Myers ER, Silva S, Coutifaris C, Carson SA, Legro RS, et al. Absence of secretory endometrium after falsepositive home urine luteinizing hormone testing. Fertil Steril. 2004;82(5):1273-7.

70. Tsampoukos A, Peckham EA, James R, Nevill ME. Effect of menstrual cycle phase on sprinting performance. Eur J Appl Physiol. 2010;109(4):659-67.

71. Elliott-Sale KJ, Ross E, Burden R, Hick KM. BASES Expert Statement on Conducting and Implementing Female Based Research. The Sport and Exercise Scientist. 2020;Issue 65. 
72. Kovanen V, Aukee P, Kokko K, Finni T, Tarkka IM, Tammelin $\mathrm{T}$, et al. Design and protocol of Estrogenic Regulation of Muscle Apoptosis (ERMA) study with 47 to 55-year-old women's cohort: novel results show menopause-related differences in blood count. Menopause. 2018;25(9):1020-32.

73. Patino CM, Ferreira JC. Internal and external validity: can you apply research study results to your patients? Jornal brasileiro de pneumologia : publicacao oficial da Sociedade Brasileira de Pneumologia e Tisilogia. 2018;44(3):183.

74. International Olympic Committee. https://www.olympic.org/ women-in-sport/background
75. Brown JB. Types of ovarian activity in women and their significance: the continuum (a reinterpretation of early findings). Hum Reprod Update. 2011;17(2):141-58.

76. Elliott-Sale KJ, Hicks KM. Hormonal-Based Contraception and the Exercising Female. In J. Forsyth, \& C-M. Roberts, editors. The Exercising Female: Science and Its Application. London: Routledge; 2018.

77. British National Formulary BMJ Group and the Royal Pharmaceutical Society of Great Britain. Germany: GGP Media GmbH; 2019.

\section{Authors and Affiliations}

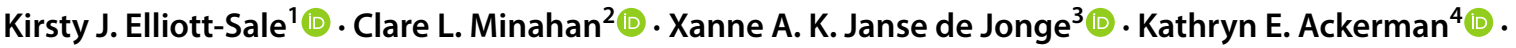

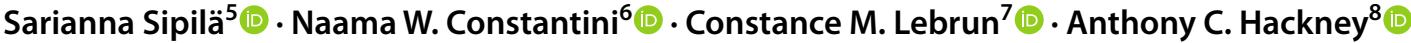

1 Sport Health and Performance Enhancement (SHAPE)

Research Centre, Department of Sport Science, Nottingham

Trent University, Nottingham, UK

2 Griffith Sports Science, Griffith University, Gold Coast, QLD, Australia

3 School of Environmental and Life Sciences, The University of Newcastle, Ourimbah, NSW, Australia

4 Division of Sports Medicine, Boston Children's Hospital; Neuroendocrine Unit, Massachusetts General Hospital, Harvard Medical School, Boston, USA

5 Gerontology Research Centre and Faculty of Sport and Health Sciences, University of Jyväskylä, Jyväskylä, Finland
6 Heidi Rothberg Sport Medicine Centre, Shaare Zedek Medical Center, Hebrew University of Jerusalem, Jerusalem, Israel

7 Glen Sather Sports Medicine Clinic and Department of Family Medicine, Faculty of Medicine and Dentistry, University of Alberta, Alberta, Canada

8 Department of Exercise and Sport Science; Department of Nutrition, University of North Carolina, Chapel Hill, NC, USA 